\title{
Issues of Utilizing Social Networking as an Informal Organizational Communication Channel: Evidence from China
}

\author{
Songbai Liu ${ }^{1} \&$ Lu Guan ${ }^{2}$ \\ ${ }^{1}$ Panyapiwat Institute of Management, Thailand \& Beijing Normal University, China \\ ${ }^{2}$ Associate Professor, International Business School, Beijing Normal University (Zhuhai), China \\ Correspondence: Songbai Liu, Beijing Normal University, China. E-mail: liusb@bnu.edu.cn
}

Received: September 10, 2020

Accepted: October 20, 2020

Online Published: November 19, 2020

doi:10.5539/ijms.v12n4p43

URL: https://doi.org/10.5539/ijms.v12n4p43

\begin{abstract}
Social networking has been increasingly used by both individual and organization in the workplace. This paper addresses gaps in the current literature and tries to demonstrate the negative impacts and consequences of social networking. Qualitative study is applied in this study, including the conduction of user survey, interviews and case studies, which are conducted in the context of China. The article reports on work in progress on the research. The early findings highlight that despite the benefits generated by social networking, issues are also obvious, including such as data security, privacy protection, work-life imbalance, increased work pressure and stress, boundary and role ambiguity. Such findings contribute to organizational policy making and generating modern management practice in the context of information society.
\end{abstract}

Keywords: social networking, informal communication, impact, user perception, China

\section{Introduction}

The past 10 years have witnessed the emergence and increasing popularity of various social networking platforms, which has greatly changed those traditional interpersonal communication styles and has become an important part of people's daily life. As a result, a variety of social networking platforms developed dramatically around the world, such as Facebook, Twitter, Instagram, Wechat, and etc. For example, a statistic of Facebook (the most popular social network platform worldwide) shows that it had 2.701 billion monthly active users, which are those which have logged in to Facebook during the last 30 days, as of the second quarter of 2020, compared with 100 million in the 2008 (Statista, 2020). Another example is Wechat (Tencent technology, 2020). This Chinese social networking platform had 1.206 billion monthly active users in the second quarter of 2020, and $25 \%$ of the active daily users switch on Wechat more than 30 times a day, and $55.2 \%$ of users use it more than 10 times. As the most popular social networking channel in China, nearly a half of the active users have more than 100 Wechat contacts.

The impacts of extensive usage of social networking platform are not only on personal life but also on organizational communication. There are plenty of researches in the literature focusing on the adoption and application of social networks as an informal communication either internally or externally (e.g., El-Haddadeh et al., 2012; Correia et al., 2014; Ou et al., 2013; Ruehl \& Ingenhoff, 2015; Khan \& Khan, 2011; Indrupati \& Henari, 2012). In particular, issues of why and how to adopt social networking services as an effective communication channel have been studied. The benefits of the modern social networking on traditional organizational communication are highlighted, especially considering the fact that Millennials the biggest generation worldwide are entering the workforce and are dramatically changing expectations as consumers and daily practice in the workplace. Benefits of using social networks as a communication channel for the organization are obvious. Firstly, more and more companies have opened an official account on either Twitter, Facebook or Wechat, and it is believed that the adoption of social networking in corporate communication can offer a more dynamic engagement between outsiders (for example, consumers and job applicants) and organizations (Ramzi et al., 2012). Therefore, social networking platform can be a useful marketing tool for companies (e.g., Correia et al., 2014; Indrupati \& Henari, 2012; Harris \& Rae, 2009). Secondly, the use of social networking is also believed to be beneficial to foster communication within organization and inter-departmental team working, which would lead to better ways of working and increased levels of employee productivity and satisfaction (Khan \& Khan, 2011; Bennett et al., 2010). Thirdly, social network is believed to be beneficial to an 
individual's career development, that is because nowadays personal success highly depends on the shape and size of his/her social network and ability to network and form connections with other social groups (Bosque, 2013), and social networking platforms provides a new way to make new friends much more efficiently and effectively. Social networking in the workplace also helps to facilitate and accelerate knowledge transfer by enhancing collaboration of employees (Bennett et al., 2010).

Though findings in the literature suggest that the business advantages and benefits of social networking in the workplace are still very much underappreciated and undervalued (Bennett et al., 2010), impacts of social networking in the workplace are not merely positive. However, most of the research in the literature tried to prove the values of social networking technology in the workplace, rather than discussing the potential risks to both the individual and the organization. Risks of utilizing social network in the workplace need to be explored and to be better managed. Considering the changing workforce profile and the development of information technology, it is meaningless to argue whether or not social networking benefits both individual and organization in the workplace. As we all know, social networks on the internet are the unbeatable trends for the future, and that is the new generations' preference of communication style. But, while encouraging and promoting social networking in the workplace, its potential drawbacks both to the individual and organization need to be aware. The purpose of this paper is to explore empirically the impacts of social networking as an informal communication channel in the workplace within the context of China. It draws particular attentions to the negative consequences of individual employee's extensive usages of such a more open, modern, and informal communication styles. Therefore, research question of this paper is what are the issues related to social networking as an informal organizational communication channel? It is believed that a better understanding of social networking's consequences would help for its future development and also benefit both individual and organization development, for example for organizational policy making.

\section{Empirical Study}

\subsection{Research Methods}

Our study is constructed through evidence from four core elements. Firstly, we undertook an extensive analysis of secondary material, which incorporated evidence from China and beyond, to develop the functional classification and theoretical analysis of social networking. We collected and compared data of different social networking platforms worldwide, and we also analyzed the current practice of utilizing social networks as an informal communication channel within organizations around the world.

Secondly, research focus is then placed on the evidence from China. Understanding can be facilitated by gathering insights through work experience and an informal process of participant observation. Since social and economic reform began in the 1980s in China, the country has experienced profound transformation and marketization (Warner, 2002). Since China began to open up and reform its economy in 1978, GDP growth has averaged almost 10 percent a year, and more than 850 million people have been lifted out of poverty. Today, China is an upper-middle-income country and the world's second largest economy (the World Bank, 2020). Having the biggest population of social networking platform user and the biggest population of millennials in the world, evidence from China could provide useful insights of the impacts of social networking in the workplace. Yet, as reported by the World Bank's research, China remains a developing country and rapid economic ascendance has brought on many challenges as well. We believe that this background of China would provide valuable but distinctive findings of the research.

Thirdly, the research aims to provide an overview of the perceptions of user regarding the use of social networking in their professional lives. Given the exploratory nature of the questions and issues outlined above, we undertake a national survey. This survey is administered to a random sample of respondents at various organizations. The questionnaire reflected a piloting exercise. Respondents are asked to identify their adoption for social networking, and to express their opinions about and perceptions towards using social networking in the workplace.

Fourthly, to strengthen the empirical-base, we hold semi-structured interviews with social networking users including both individual employees and managers, lasting from half to over 1 hour. In developing the questions, a pilot study was conducted for refining the interview questions and process. With the interviewee's permission, all the interviews will be recorded, transcribed and content analyzed. This aspect adopts a case study methodology. We are going to undertake five comparative case studies. Companies were selected to reflect a cross-section of institutions regarding factors like type, size and etc. Prior to interviews substantive data about each company was collected; sources included managerial memorandums, policy literature, community newsletters, financial statistics and reports into specific issues or projects. This information enabled us to 
appreciate the organisational context within which the interviewees operated, to refine questions to reflect those circumstances and enhanced our overall findings.

\subsection{Key Findings}

We are still in the early stage of this research, and the below findings are summarized from our early studies of second-hand data and pilot studies.

\subsubsection{Individual Usage of Social Networking}

Results of the pilot survey show that adoption rates of social networking are high, with $92 \%$ of the respondents reporting an account in at least one social networking platform, and $85 \%$ of the respondents have more than two social networking account. Millennials (i.e., those age group between 18-36 years old) have the highest adoption rate for social networking. These findings consist with the marking statistic of social networking platform worldwide. For example, according to WeAreSocial's research in the 2016, the active user population of Chinese QQ was in the top three social networking platforms in the world.

As for the normal practice of using social networking, nearly $80 \%$ of the respondents have used their private account of either QQ or Wechat to contact co-workers and customers. $67 \%$ of the respondents log-on to their private social networking account during working hours. For millennials, social networking platforms such as QQ and Wechat have already replaced phone and email as the preferred communication channel in the workplace while the older generation still preferred using phone and text message at work.

Social networking platform has been seen by respondents as an important and necessary channel to develop and maintain business network. Findings show that nearly a half of the active users of Wechat have more than 100 contacts, and more than half of these contacts were built on works relations, including such as co-workers, previous colleagues, customers and etc.

Also, $63 \%$ of the respondents reports that they have joined into more than ten various professional groups on social networking platform, and $55.2 \%$ of them use these groups for either formal or informal communication more than 10 times a day.

Despite of the speed and economic consideration of using various social networking platforms for work, concerns are expressed from our pilot study, including both survey and interviews. The main issues are briefly discussed as below.

\subsubsection{Data Security Issues}

For individual user, privacy is the main concerns of respondents. As the result of dramatic development of mobile network in recent years, the function of 'share my moments' on social networking platforms has become more and more popular. Even though the users can select to hide individual's moments from certain contacts, pilot study in this research shows that as the increasing number of contacts on their social networking account, the management of individual moments has unfortunately become more and more difficult. For example, $35 \%$ of the respondents admit the fact that as the number of contacts increase so fast that they don't have time to choose those who need to be hidden from their personal moments. Some respondents even claimed that they have already dropped sharing moments or reduced the frequency of sharing. Moreover, concerns of privacy not only come from the actively sharing your moments, but also are the result of excessive data generated by all sorts of social networking activity.

For the organizations, consequence of data security caused by social networking platforms can be serious. Many of the mangers during our pilot interviews raised the common difficulty of protecting business data given the speed and cost of using social networking as an informal business communication channel. There are many examples and case revealed in the interviews to illustrate the data security issues facing organizations following the adoption of social networking as one of the popular communication channels.

\subsubsection{Boundary Issues}

As the increasing usage of social networking platforms at work, traditional top-down communicaiton style in the workplace has been increasly replaced with a modern and more open style. As a result, the boundary between formal and informal organizational communication became blur. The mangement of informaiton is getting harder and harder. Many of the respondents claimed that there they were in many different work groups on the social networks (e.g., inter-work team/project team, departmental basis or business unit basis, etc.), which were created either officially or unofficially. Some of them were effectively managed while some were not. The authenticity of information thus became an issue. For example, employees can originate incorrect information which is easily and fast shared within the organization. 
Boundary issues are also caused by the role ambiguity of individual employee in various social netwokring platform. As outlined above, many respondents are using private social networking accounts on various platforms for the purpose of daily business contact. It is not difficult to understand that these social networking users sometimes would be confused in terms of 'who i am' and 'who i am talking to'. Some of them complained that even though they expressed their own individual views on these platforms, they were easily to treatd as a kind of offical opionion, which did bring to serious consequences. There are examples obained during the interviews to provide evidence.

\subsubsection{Work-Life Balance Issues}

The majority of reseach respondents admited that the increasing usage of social networking platforms at work had brought to more work stress and pressures. It is the fact that such communicaiton chanel has provided great convenience for users, and of course value for money. But the downside is you have to reply so many messages, inquiries and etc everytime, which are much more than the number of emails and phone messages in the past.

Responses from both questionnaires and interviews show that most people expect an instant reply of QQ message or Wechat message. Considering the popularity of mobile network in nowadays, people tends to have less patience during communication. Moreover, the convenience of communication means individual employees can be easily contacted at anytime anywhere. All of these above have brough to the negative effects on making work-life balance, which has been one of the dominate work value of millennials. As one the interviee commented on that, 'it is not polite to ignore those messages on Wechat received during weekend or after business hours, but such communication has taken lots of my personal time, which is unfair'.

\subsubsection{Challenges to Existing Management Theories}

Pilot interviews conducted in the early study in our research show that the adoption of social networking as an informal organizational communication channel has created new challenges to those existing management practice. These include the increasing fragmentation of organizational structure, the trend of boundless organization, decentralized leadership, difficulty of on-the-job performance monitor, and etc. Many of the new practices and the following issues are not covered in the traditional management theories. That is one of the main reasons that some organisations in our case studies prohibit or restrict social networking in the workplace. Fear, resistance and risk are the opinions that still dominate some of the organisations.

\section{Discussion}

As said before, we are still in the early stage of this research. Since the process of data collection has not been finished, analysis and discussion do not have a sound basis generated from the research findings. However, the early findings obtained from the pilot study do explain some of the theories in the literature. Firstly, social capital theory helps to explain both individual and organizational motive of using social networking techniques in terms of developing and maintaining business relations.

Secondly, Social identity theory would also help to further explore the boundary issues and to discuss the potential consequences of employee's role ambiguity following the use of social networking in the workplace.

Thirdly, a modern management practice is called for facilitating the future utilization and development of social networking services in the workplace, especially in fields of policy making and process redesign. For example, effective protection, ethical utilization and management of personal data should the responsibility of both the social networking service providers and the users themselves. Companies therefore need to pay attention to provide training and support to employees in using various social networking services at work.

Fourthly, following the extensive usage of social networking, online community is growing speedily as a kind of virtual society. Compared with the systematic regulations of our society in reality, laws for the online interaction are lacking and far lag behind the practice. Given this context, organizations who are adopting social networking (or are going to adopt it in the near future) as an information informal communication channel need to be aware of all the potential risk and negative consequences. Only by building up such understanding can it achieve a smooth development in the future.

\section{References}

Bennett, J., Owers, M., Pitt, M., \& Tucker, M. (2010). Workplace impact of social networking. Property Management, 28(3), 138-148. https://doi.org/10.1108/02637471011051282.

Bosque, D. D. (2013). Will you be my friend? Social networking in the workplace. New Library World, 114(9/10), 428-442. https://doi.org/10.1108/NLW-04-2013-0033

Cheung, C., Lee, Z. W. Y., \& Chan, T. K. H. (2015). Self-disclosure in social networking sites: The role of 
perceived cost, perceived benefits and social influence. Internet Research, 25(2), 279-299. https://doi.org/10.1108/IntR-09-2013-0192

Correia, P. A. P., Medina, I. G., Romo, Z. F. G., \& Contreras-Espinosa, R. S. (2014). The importance of Facebook as an online social networking tool for companies. International Journal of Accounting \& Information Management, 22(4), 295-320. https://doi.org/10.1108/ijaim-08-2013-0050.

El-Haddadeh, R., Weerakkody, V., \& Peng, J. (2012). Social networking services adoption in corporate communication: the case of China. Journal of Enterprise Information Management, 25(6), 559-575. https://doi.org/10.1108/17410391211272838.

Harris, L., \& Rae, A. (2009). Social networks: the future of marketing for small business. Journal of Business Strategy, 30(5), 24-31. https://doi.org/10.1108/02756660910987581.

Indrupati, J., \& Henari, T. (2012). Entrepreneurial success, using online social networking: evaluation. Education, Business and Society: Contemporary Middle Eastern Issues, 5(1), 47-62. https://doi.org/10.1108/17537981211225853

Khan, A., \& Khan, R. (2011). Informal communication styles benefit McDonald's and Ford: The way ahead in an era of social networking. Human Resource Management International Digest, 19(7), 27-29. https://doi.org/10.1108/09670731111175560

Ou, C. X., Sia, C. L., \& Hui, C. K. (2013). Computer - mediated communication and social networking tools at work. Information Technology \& People, 26(2), 172-190. https://doi.org/10.1108/ITP-04-2013-0067

Ruehl, C. H., \& Ingenhoff, D. (2015). Communication management on social networking sites: Stakeholder motives and usage types of corporate Facebook, Twitter and YouTube pages. Journal of Communication Management, 19(3), 288-302. https://doi.org/10.1108/JCOM-04-2015-0025

Statista. (2020). Facebook: number of monthly active users worldwide 2008-2020. Retrieved from http://www.statista.com/statistics/264810

Tencent technology. (2020). The impacts of Wechat. Retrieved from https://mp.weixin.qq.com/s/UHHwii2qlbcfABwGHX6FQA

The World Bank. (2020). China Overview. Retrieved from http://www.worldbank.org/en/country/china/overview

Ubeda, J. E., Gieure, C., \& Carlos de - la - Cruz, S. O. (2013). Communication in new technology based - firms. Management Decision, 51(3), 615-628. https://doi.org/10.1108/00251741311309689

Van Zyl, A. S. (2009). The impact of Social Networking 2.0 on organisations. The Electronic Library, 27(6), 906-918. https://doi.org/10.1108/02640470911004020

Warner, M. (2002). Globalization, Labour Markets and Human Resources in Asia-Pacific Economies: An Overview. International Journal of Human Resource Management, 13, 384-398. https://doi.org/10.1080/09585190110111431

WeAreSocial. (2016). 2016: Active users by social platform. Retrieved from http://www.199it.com/archives/461173.html

\section{Copyrights}

Copyright for this article is retained by the author, with first publication rights granted to the journal.

This is an open-access article distributed under the terms and conditions of the Creative Commons Attribution license (http://creativecommons.org/licenses/by/4.0/). 